\title{
ENHANCING SERVICE DELIVERY IN LOCAL GOVERNMENT: THE CASE OF A DISTRICT MUNICIPALITY
}

\author{
DALENÉ PRETORIUS \\ WILLEM SCHURINK \\ wjs@webafrica.org.za \\ Department of Human Resource Management \\ University of Johannesburg
}

\begin{abstract}
This article offers a leadership. It offers a leadership model for enhancing service delivery within local government. Applying modernist qualitative methodology, particularly a combination of casing and grounded theory, the study offers the Retro Advanced Leadership Model which comprises (1) management of leadership performance, (2) legislative imperatives, (3) the achievement of realistic goals, and (4) continuous maintenance and monitoring of achievements. Key implications and recommendations are provided.
\end{abstract}

Key words: Leadership performance, governance, service delivery, monitoring, grounded theory

Post-apartheid South Africa faces a major challenge in ensuring that municipalities provide optimal and professional services to citizens of heterogeneous cultures. The Minister of Provincial and Local Government, Minister F.S. Mufamadi, stated the following in the debate on the State of the Nation Address of President Mbeki on 11 February 2005: "In designing the new system of local government, care was taken to ensure that we put in place, a framework for progressively doing away with the consequences of a system which exposed White and Black South Africans, to vastly different socio-economic environments. The continuing challenges we face therefore, is one of ensuring that all municipalities develop the requisite capacity to translate those resources into instruments with which to confront problems of poverty and underdevelopment. The interventions must make positive impact on the way we meet such challenges as: public participation, programme management as well as creating conditions for sustainable service delivery and economic development (Mufamadi 2005, p. 1). This statement by the minister underscores the importance of service delivery at ministerial level. The monitoring of service delivery needs through effective governance and service administration is clearly crucial. This study is based on the belief that this is only possible through enhancing leadership in the local government sphere.

In post-apartheid South Africa, access to effective public services is no longer seen as an advantage enjoyed by only a privileged few in the community, but as a legitimate right of all residents, particularly those who were previously disadvantaged. This stance emphasizes "service to the people" as parameter for local government transformation. Thus one of the most important indicators in assessing the transformation of local government is the experiences and perceptions people have of service delivery in their day-to-day lives, more specifically whether they perceive an improvement in the services delivered to them. The implication of this is for local government to transform words into deeds, and thus to prioritize and satisfy the needs of the communities they service.

Attempting to provide a framework for people-centred public service delivery the South African government introduced Batho Pele (derived from a Sesotho word meaning "putting people first") in 1997 (http://www.dpsa. gov.za/batho-pele/index. asp). This initiative strives towards moving public servants to become service orientated, to pursue excellence in service delivery and to commit themselves to continuously improve service delivery. It also sets the principles for transforming service delivery with regard to consultation, service standards, access, courtesy, information, openness and transparency, redress and value for money. These principles are required, since it is argued that a transformed local government needs to be measured against its commitment to continuous service delivery improvement. ${ }^{1}$

Rapid changes fuelled by the world economy and technology have been forcing organizations to transform themselves in order to become more responsive and competitive. As Day and Halpin (2004, p. 3) correctly point out, this has resulted in "a pervasive need for people at every level to participate in the leadership process". (Emphasis added.) Since no single leader has all the answers to all problems, all members or employees of an organization, as far as possible, need to be leaders. Moreover, established leaders need to be better prepared to participate in leadership (Day \& Halpin, 2004). While the scope of the current "crisis" in leadership is debatable, many contemporary scholars, practitioners and policy makers would agree that there is a pressing need to develop leadership more fully in organizations (Day \& Halpin, 2004). In fact, according to the Batho Pele principles, good leadership is one of the most critical ingredients or successful organizations (http://www.dpsa.gov.za/batho-pele/ index.asp).

The above statements emphasize that leadership qualities are needed to improve service delivery in local government, adjust to the ever-changing demands of local authority as well as address the inequalities of the past. Moreover, local government needs to change from an institutional to a developmental organization. Vehicles to achieve these objectives are not embedded and in the external organizational sphere (public-private partnerships and small, medium and micro enterprises), but also in the workplace conditions of service, and the quality and sustainability of the internal working environment (District Municipality IDP and IDP Review).

From local newspapers as well as news bulletins appearing on national television it is clear that demands made by South African communities for service delivery from municipalities have escalated. Local government has been in the news, sometimes for days on end particularly, in areas where communities have made forceful requests for improved services. Complaints and demands have not only been made for services such as water and electricity, but residents have also claimed houses from local government. More recently, residents have embarked on mass action to underline their demands.

In the light of these events it is now crucial for the South African Government not only to ensure that practical steps are taken to implement "Vision 2014" and the "Apex Priorities" recently 
announced by President Thabo Mbeki (Mbeki, 2008), but also to monitor and evaluate these steps. Thus it is critical that the promise made by the African National Congress (ANC) in 2004 regarding the implementation of an improved monitoring system be realized, since this could, over the next few years, help to set our country on the road to faster realization of the ideals of our Constitution. In this regard President Mbeki stated: "We shall continue this year to intensify efforts to strengthen local government capacity in line with the 5-year Local Government Strategic Agenda. To ensure systematic monitoring in this regard, SALGA has agreed to provide quarterly reports on the work being done" (Mbeki, 2008, p. 4).

With regard to the role of leadership, Vil-Nkomo's (1998, p. 201) statement is apt: "South African cities are faced with tremendous development challenges. There is, however, a critical institutional developmental challenge, which constitutes the crux of the success or failure of municipal leadership. ${ }^{2}$ To achieve success, specific leadership skills are needed to improve service delivery in local government in South Africa. More specifically, skills are needed to address the ever-changing demands for improved services placed on local authority as well as the need to address the inequalities of the past. Achieving these objectives also calls for skills in the establishment of public-private partnerships and small, medium and micro enterprises, as well as the improvement of conditions of service and the quality and sustainability of the internal working environment. Given the challenges confronting leaders in the public service today, "a need exists to develop new skills of leadership at the same time, and to be in a position to address the salient issues of conflict of interest. Technical or functional skills are no longer sufficient. Leaders are required to be strategic, to lead beyond boundaries, and importantly to keep sight of the vision ahead with their feet firmly on the ground." (Emphasis added.) These views tie in with local government's strong emphasis on innovation, communication, skills transfer and development in enhancing service delivery on ground level. In short, these leadership qualities should help local government to make the much needed transformation from an institutional to a developmental organization.

The aim of this study was thus to develop a leadership construct that could assist local government to achieve optimal service delivery and reach set goals aligned with the South African Constitution (Republic of South Africa, 1996).

\section{RESEARCH DESIGN}

\section{Research approach}

Pretorius opted for symbolic interactionism ${ }^{3}$ as theoretical perspective. Keen to develop a substantive tool $^{4}$ by using grounded theory and following a modernist qualitative approach, she chose a case study ${ }^{5-6}$ design. More particularly, in terms of Bogdan and Biklen's (1998) exposition, the study represented (1) an observational case study (participant observation supplemented by interviews and documents focusing on leadership in the District Municipality), (2) a multi-case study (more than one of the leaders in the District Municipality were studied, and (3) a situation analysis (leadership qualities were researched with the aim to enhance service delivery).

\section{Research methodology}

Participants

The study was conducted in a district municipality located in South Africa's Gauteng Province. ${ }^{7}$ This district municipality was established in terms of section 12 of the Municipal Structures Act by Notice 141 published in Provincial Gazette Extraordinary dated 1 October 2000 (as amended).

It was argued that by interviewing four individuals who had substantive experience in this environment, rich material would be generated to explore and describe (1) leadership, (2) client focus, (3) corporate culture, (4) business results, and (5) transformation. The study was guided by the following research question: "Which leadership qualities are required and how should these be implemented to ensure optimal service delivery by local government"? Careful consideration was given to the question: "Who should be approached to take part in the research?" It was decided to involve the managers responsible for service delivery in the district municipality where Pretorius (2006) was employed. Having been an employee at this local government institution for 12 years, Pretorius realized that in order to gain the rich material that qualitative research demanded, her ideal sample needed to consist of the top two levels of decision makers. She therefore approached the Municipal Manager and the three employees directly accountable to him, namely the Chief Financial Officer, the Strategic Executive: Service Delivery and the Strategic Executive: Health and Community Services to participate in the study.

\section{Methods of data gathering}

Qualitative researchers generally rely on four basic types of data sources: interviews, observations, documents and audio-visual materials (see Creswell, 1998). Eager to capture, describe and appreciate the characteristics of leaders responsible for service delivery, and to find out how they address challenges and manage difficulties they experience in the execution of their day-to-day activities, Pretorius employed all of these methods as well as theoretical concepts derived from the literature and municipal documents.

\section{Documents}

Pretorius scrutinized media reports and press statements as well as official reports and files (unsolicited documents). To be able to understand and interpret the experiences and viewpoints of the participants against their different backgrounds, she used socio-demographic information gained from the personal files of the participants. The accuracy of these data was verified during the first interviews with the participants. In addition, the participants provided essays and/or diaries (see Zimmerman \& Wieder, 1977) (solicited documents) on request. Pretorius also kept a project diary outlining important decisions and dates. ${ }^{8}$

\section{Face-to-face interviews}

As Bogdan and Biklen (1998, p. 35) state, "qualitative researchers are interested in how people act and think in their own settings; they attempt to 'blend into the woodwork', or to act so the activities that occur in their presence do not differ significantly from those that occur in their absence". The interviews were therefore conducted in the research setting where participants felt comfortable. The following warning of Bogdan and Biklen (1998, p. 35) was heeded: "If you treat people as 'research subjects,' they will act like research subjects, which is different from how they usually act." Pretorius (2006) took special caution not to treat the participants any different from her normal day-to-day interaction with them. Thus she went out of her way to treat them as leaders in the organization. Since all the participants were her seniors, none of them had any reason to feel threatened by her in any way.

2 Municipal leadership in this regard has to be taken to include political leadership (executive and legislative) as well as those officials charged with the responsibility to execute and manage policies developed at the political level. 3 This theoretical perspective is described in Bogdan and Biklen $(1998,2003)$, Bogdan and Taylor (1975), Taylor and Bogdan (1998), Glaser and Strauss (1967), Lincoln developed at the political level. 3 This theoretical perspective is described in Bogdan and Biklen (1998, 2003), Bogdan and Taylor (1975), Taylor and Bogdan (1998), Glaser and Strauss (1967), Lincoln
and Guba (1985), Lofland (1971), and Lofland and Lofland (1995). 4 In terms of Mouton and Marais (1990), Graser and Strauss's (1967) proposed grounded theory may be seen as a symbolic tool that and Guba (1985), Lofland (1971), and Lofland and Lofland (1995). 4 In terms of Mouton and Marais (1990), Graser and Strauss's (1967) proposed grounded theory may be seen as a symbolic tool that
explains a particular research topic. 5 In addition to case study, Creswell (1998) identifies biography, phenomenology, ethnography and grounded theory as the qualitative traditions of inquiry or qualitative designs most commonly used in qualitative research. 6 Although the research design chosen for this study is above all a case study, it resembles grounded theory and biography in some respects. 7 In accordance with ethical practice in social science research (to protect both the research site and the research participants), the name and location of the District Municipality are not disclosed. 8 The project diary supported the construction of a natural history, originally proposed by Becker (1970) crucial for the establishment of a study's credibility (see Athens, 1984; Schurink, 1989; Silverman, 2000). This approaches what has become regarded as an audit trail (see Schurink, 2005). 
From the outset Pretorius made it clear that, within the research context, she was interested in how the research participants thought about their lives, their experiences and particular situations (Bogdan \& Biklen, 1998). In order to capture and understand the vast experience of leadership, service delivery and transformation in local government and national policy, three rounds of interviews were conducted with each. These interviews (discussing and audio-recording key aspects or themes) yielded valuable in-depth knowledge of the participants' life world.

\section{Participant observation}

Bogdan and Biklen (1998, p. 35) state that "qualitative researchers try to interact with their subjects in a natural, unobtrusive, and non-threatening manner". As already indicated, while doing the research, Pretorius, in her capacity as manager of human resources, interacted with the research participants on a daily basis. Being a member of the management team allowed her to compare research discoveries with her personal experiences of the daily activities in the District Municipality (these expereiences were detailed in the natural history of the research). This dual role had the added advantage that the participants could openly and honestly share their opinion, since they knew that Pretorius had inside information and they had known her inti, they knew that she could be trusted.

\section{Literature study}

Relevant scholarly works, textbooks and journal articles on leadership and service delivery were scrutinized for additional insight.

Audio-visual material (see Creswell, 1998; Descombe, 1998)

The study made use of photographs to illustrate the day-to-day activities of the District Municipality.

\section{Procedure}

Data capturing and storing

As qualitative research yields a mass of material, easy retrieval for later detailed analysis had to be ensured. For this purpose Pretorius (2006) made use of field notes, transcriptions and audio recordings. Notes were made in the field, based on all conversations and observations. These notes were typed and stored directly after each interview and observation session. In addition, notes on non-verbal cues and physical circumstances were also jotted down during the interviews. The field notes formed the core of the audit trail and helped to ensure rigorous data generation and analysis (Schwandt, 2007).

\section{Data analysis and interpretation}

Various applications of grounded theory are available today. ${ }^{9}$ Pretorius followed that of Strauss and Corbin (1990). These two scholars identify two main processes of grounded theory analysis, namely coding procedures and adjunctive procedures. These processes were used to design and develop a wellintegrated set of concepts that provided a thorough theoretical explanation of the phenomenon of leadership qualities (Strauss $\&$ Corbin, 1990). According to these scholars grounded theory begins with coding, which implies asking questions and making comparisons from the basis of the analysis. The data analysis was done systematically and followed the standard format. Accordingly, the research problem was addressed by means of an analytical procedure that applies open, axial and selective coding (see Strauss \& Corbin, 1990; Dey, 1999; Creswell, 1998).

Creswell (1998) emphasizes that the process outlined above results in a substantive theory, written by the researcher close to the specific problem or people concerned. Because the researcher knows the categories from the field-based data, this theory is subjected to further empirical testing during follow-up research.
ATLAS.ti was used to code and store the text on the computer, which later enabled Pretorius to retrieve the coded text. Open coding is the practice of breaking down and conceptualizing the data (Strauss \& Corbin, 1990), starting from the moment the first data are gathered (Holloway \& Wheeler, 2002). This phase brought themes to the surface from data that were "at a low level of abstraction" and came from the initial research questions asked (Neuman, 2003, p. 443). As the coding process progressed, the level of abstraction increased. The use of ATLAS.ti enabled the retrieval of interviews with the codes attached to each of the different topics. This took care of the manual tasks associated with the coding process. However, the warning of Schwandt (2007) was heeded, namely that the use of computer-assisted data analysis systems could distance and even alienate researchers from their data. Pretorius thus also manually checked the emerging codes attached to each of the topics.

The computer effectively took over the physical task of writing marginal codes, making photocopies of transcripts or field notes, cutting out all chunks of text relating to a code, and pasting them together (Burden, 2006). However, ATLAS.ti did not do this automatically, and the data still needed to be interpreted by coding them. The software merely assisted in the systemization of the data and did not by any means contribute to the actual analysis of the data. While the computer indeed took over the manual labour involved, the main steps in the analysis of the data remained the same as those for the manual analysis.

Use was made of transcribed interviews as the main source for the open coding phase. In an attempt to ensure that the data were analyzed in a systematic and thorough manner, the strategies employed by Nell (2005) and Claassen (2004) were followed.

Pretorius read and re-read each sentence and paragraph so as to determine what it was all about. Performing the actual coding by using ATLAS.ti enabled her to break down the data into distinct units of meaning. ${ }^{10}$ Every line of the first transcribed interview was searched for key words or phrases that could give some insight into the question under study. These were then highlighted and extracted from each of the interviews (see Nell, 2005). After completing the line-by-line analysis of the first interview, the process was repeated with another interview. The interviews were analysed in this manner until recurring patterns could be detected. At this point the codes that conveyed something about leadership and seemed to have a relation to each other were clustered into groups. This started "the process of abstraction and moved the interpretation on from merely describing what was occurring, to linking concepts" (Nell, 2005, p. 68).

With the assistance of ATLAS.ti, 677 concepts were initially identified. These were reduced to 40 . The latter were then grouped together to form groups of concepts with the same or similar meaning. These groupings were then named. As an example, the label "District Municipality Challenge" was given to a group of codes that collectively described the central theme. In ATLAS.ti these groups are known as "families". ${ }^{11}$

Once the views and experiences of the participants were analyzed, the analysis was verified with the assistance of a peer who has used the same computer programme for his data analysis. Eventually the identified themes emerged through excerpts of the participants' views and stories, thus giving them a "voice". Following Claassen (2004), verbatim quotations were used to authenticate the identified trends and to explain the thinking and analysis patterns in the study.

Up to this point, no conscious attempt was made to interpret the data in relation to the themes that emerged from the data during the open coding phase. Interpretation was reserved for 
the axial coding phase, that is, appreciating concepts in terms of their interrelationships. This type of coding implies that the researcher moves to a higher level of abstraction, which is done by specifying relationships and outlining a core category around which the other concepts revolve (Goulding, 2002). She further points out that by using axial coding, the researcher develops a category by specifying the conditions that give rise to it, the context in which it is embedded, and the action or interactional strategies by which it is handled, managed and carried out. Strauss and Corbin (1990, p. 96) define axial coding as "a set of procedures whereby data are put back together in new ways after open coding, by making connections between categories". They further state that this involves intensive work with a single category, examining how it connects with other categories and also exploring its "conditions, contexts, action or interactional strategies and consequences" (Strauss \& Corbin, 1990, p. 96).

The following steps were applied during the axial coding:

ATLAS.ti was used to determine the interrelationships between the various identified categories. The various codes that were identified during open coding were grouped together to indicate the possible relationship between the codes that all related to a similar category and could logically be clustered together (Nell, 2005).

The research participants assisted in the manual coding of some of the concepts. Some concepts drawn from ATLAS.ti were printed and discussed with the aim to manually indicate the possible relations between the codes believed to be related to a category. In this way the number of themes emerging during open coding was also reduced to a more manageable number. After close scrutiny, the initial themes were explored and the relationships between them examined. This process assisted in integrating the themes with broader ones, which eventually encompassed all open coding themes.

The seven categories became the central elements of the Retro Advanced Leadership Model developed by Pretorius and were all derived in a similar way by means of the grounded theory application. Following Nell (2005) and others, member checking was applied to test the categories, that is, Pretorius returned to the participants and obtained their opinions. In fact, not only did the participants check the interpretation, but they also actively criticized it and expanded on their earlier comments.

Taking a lead from the participants who felt that some of the concepts identified were not important, the focus shifted to those they believed to be important. The goal of grounded theory is to generate a theory that accounts for a pattern of behaviour that is relevant and works for those involved (Strauss, 1987). Strauss and Corbin (1990) further explain that selective coding entails the process of selecting the central theme, which integrates all other inferred themes. This type of coding is thus the process of choosing one category to be the core category or, to put it differently, finding the engine that can drive the train. Here, the task is essentially to develop a single storyline around which everything else is draped (see Holloway \& Wheeler, 2002; Polit, Beck \& Hungles, 2001; Seale, 1999; Neuman, 2003). The criteria should fit and describe the phenomenon they stand for and be broad enough to cover subsidiary categories. As Strauss and Corbin aptly state: "The core category must be the sun, standing in orderly systematic relationships to its planets" (p. 124).

The study draped the storyline around "the leadership qualities needed to enhance service delivery in local government. In thinking about the emergence of a main theme, the following criteria identified by Strauss (1987) were used to judge which category should serve as the core category:

- To be placed in the heart of the analysis, the identified category has to be central, and thus relate more to other categories than any other category does, as well as show a relationship to as many other categories and their properties as possible.

- The core category must appear frequently in the data and form a pattern.

- The core category must relate to other categories easily, but because of its relationship to many other categories it will take longer to saturate.

A core category should have clear implications for the formation of a grounded theory. Thus the development of a core category should lead to the emergence and further development of the theory.

The core category not only allows for the development of a pattern, but should also allow for building the maximum variation for the analysis, since coding is done in terms of its dimensions, properties, conditions, consequences, strategies etc.

In conclusion: During the data analysis, Pretorius wrote personal notes regarding themes, and identified existing linkages that ultimately assisted in the crystallization of the core theme. In these notes, she also indicated how some of these themes related to the literature. Finally, she linked all the themes to the core theme of "leadership qualities needed to enhance service delivery in local government".

\section{FINDINGS}

Municipal service delivery is governed by (1) the Integrated Development Plan and the Performance Management System; (2) intergovernmental relations; (3) the Expanded Public Works Programme; (4) Batho Pele; (5) the budget; and (6) policy and procedure. The study focused on policy and procedure.

When focusing on policy and procedure, it becomes clear that the role of the District Municipality in the national imperative has altered radically over the past few years. Parliament and provincial governments' expectations of the District Municipality and of local municipalities have changed drastically. The sleepy provider of municipal services has come to be seen as the vehicle that not only carries the hopes of the nation in delivering basic services but is also responsible for the upliftment of communities and the creation of job opportunities. In fulfilling these expectations, the District Municipality must become a dynamic organization that demonstrates ingenuity, efficiency, transparency and accountability. The District Municipality is as a vital entity in local government that must carry out the critical function of service delivery to all citizens in its area of jurisdiction.

In order to give effect to the aforementioned expectations, the identified District Municipality adopted eight priorities that are in line with the ANC Manifesto, namely (1) promotion of access to land; (2) poverty alleviation; (3) stimulating economic growth; (4) health care and HIV/Aids controls; (5) public safety; (6) job creation and skills development; (7) public and infrastructure development and maintenance; and (8) good and democratic governance.

The four participants may be regarded as elite members of the District Municipality. However, it became clear that although the different problems they experienced were limited to their particular fields of expertise, they shared the same sentiments on components of service delivery such as lack of funding, resources, communication etc. Nevertheless, despite these difficulties the leadership of the District Municipality continued to pursue creative and innovative ways of improving the financial, administrative and service delivery capacity within the region. 
The leaders were also aware of the need to strengthen the ward committee structures in order to bridge the gap between government planning and programme implementation on the one hand, and community involvement on the other hand. They realized the importance of empowering the communities to fight poverty, creating job opportunities and ensuring meaningful development in their area. This would raise the credibility and integrity of local government and promote integrated development planning.

As already stated, it is now crucial for the South African Government to ensure that practical steps are taken to implement the goals set by "Vision 2014" and the more recent "Apex Priorities" (http:// www.info.gov.za/speeches/2008/08020811021001.htm) and thus to fulfil the promises made to the people. Local government is a kingpin in helping to accelerate progress towards the achievement of these objectives. In this regard, local economic development could play a major role, since it empowers communities to fight poverty and create job opportunities, and ensures meaningful development for local communities.

The District Municipality faces the following challenges:

- Promoting a seamless, open, ethical, professional and accountable system of governance.

- Ensuring service excellence through appropriate institutional arrangements and competent and committed politicians and officials who reflect the community's demographic profile.

- Improving equitable access to social services and infrastructure.

- Co-ordinating and supporting the creation of an enabling environment for sustained economic growth and development.

- Facilitating integrated development that does not harm the ability of future generations to sustain it.

- Transforming the District Municipality to ensure effective and efficient service delivery to its communities.

- Facilitating new core management systems in order to pursue the developmental path mapped out by the District Municipality and other spheres of government.

- Developing procedures to ensure that resources and activities are aligned with the Integrated Development Plan (IDP).

- Ensuring funding for prioritized projects to meet the challenges of service delivery and to address infrastructure backlogs.

- Stimulating local economic development.

Speeding up the progress in the right direction could also contribute towards improving the credibility and integrity of integrated development plans and local economic development projects. It is therefore essential for each district municipality to identify the obstacles holding it back from reaching the set goals. The difficulties in reaching the goals set by the District Municipality as experienced by the participants were the following:

\section{No clear distinction between functions}

No clear distinction exists between functions to be performed respectively by dDistrict and local municipalities. Certain functions seem to overlap. Research participant 1 stated:

"Taking into consideration the position of the District Municipality in accordance with your Municipal Structures Act, there is no clear division of functions still at this stage between the District Municipality and the local municipalities." The participant continued: "Because there is no clear division of functions, this resolved in a reluctance to cooperate from Local Municipality side and it hampers the execution of resolutions and activities throughout the region."

From the study it was clear that the lack of co-ordination and even co-operation between district and local municipalites poses a major challenge and needs to be urgently addressed in order to enhance service delivery, especially with development planning and the compilation of integrated development plans. It was emphasized that the task of the District Municipality was to co-ordinate functions:

"Our role as the District Municipality, we are coordinators, I think that I have not emphasized that enough, we are supposed to coordinate, we find ourselves doing the job, and the staff on the structure that we have, is not for doing the job, is for doing the job of coordinating, not of being, you know... on hands with it."

However, this problem should be addressed once the Intergovernmental Relations Framework Bill [B3B-2005] is enacted. The objective of this Bill is to provide, within the principle of co-operative governance set out in Chapter 3 of the Constitution, a framework for the national government, provincial governments and local governments, and all organs of state within those governments, to facilitate co-ordination in the implementation of policy and legislation, including (1) coherent governmen, (2) effective provision of services, (3) monitoring implementation of policy and legislation, and (4) realization of national priorities. The enactment of this Bill could also improve co-ordination of resources and affect budgets between local governments and between provincial departments and local government.

\section{Tedious procedures}

Procedures of approval are too tedious. This could be corrected through proper delegation of powers, as the research participants suggested:

"In order to enhance service delivery the methods and processes must be more speedily, there must be more funds towards infrastructure to stimulate development. Ffrom my point of view most emphasis is placed on housing development without taking into consideration that infrastructure is needed to make the housing development self-sustainable."

"There needs to be a structure that will be looking specifically at policy-making whilst it was also stressed by research participant 3 that there needs to be a unit to look at service delivery as we must let people know about services right down in an efficient and effective manner. If we have systems that will guide the unfolding of local government services it will help. At the moment the system in local government to look at service delivery is very weak. Legislation is very well, but the system and mechanisms to let the legislation unfold is lacking."

"Systems should be driving new ways of doing things. Such systems should be driving the concept of district or regional management and therefore people should attend courses in order for national government to assist municipalities so that transformation that happens in local municipalities or in local government is actually transformation that is in line with what happens nationally as well as provincially" (participant 3).

The administrative procedures that must be followed in order to obtain approval from the Council are hampering progress. The study showed that if the delegated of powers of the Strategic Executive: Service Delivery and those of the Strategic Executive: Community Services could be expanded-; decision-making on service delivery issues could be expedited.

Research participant 1 emphasized that the role of the District Municipality in this regard is to follow a holistic approach whereby only projects that could benefit the region as a whole must be embarked upon. This would also link to the establishment of supportive governance, whereby local municipalities can provide the necessary support to one another

\section{Lack of integration and co-ordination}

Within any local area many different agencies contribute to development, including national and provincial departments, 
parastatals, trade unions, community groups and private sector institutions. It was indicated that poor co-ordination between service providers could severely undermine the development effort.

Lack of integration between land-use and transport planning is an example of the above that needs to be addressed. Township development takes place without taking cognizance of accessibility to existing routes and proximity to amenities. This delays the implementation processes and at the end of the day service delivery is not visible in the community.

Derived from the individual local municipal spatial development frameworks, provincial studies and national policies, the District Municipality Spatial Development Framework was established to give guidance to the spatial structuring of the local municipalities falling under its jurisdiction. In this regard, the purpose of the District Municipality Spatial Development Framework is, firstly, to assess the position of the District Municipality from a national and provincial perspective and, secondly, to serve as a guide for the respective local municipalities in order to ensure that their spatial development initiatives link to the overall development perspective for the district. The main purpose will therefore be to ensure that the district as a whole contributes towards the orderly spatial development of the Gauteng Province.

The District Municipality Spatial Development Framework focuses primarily on macro development trends and proposals, integration and linkages.

Research participant 3 stressed that the objectives of residential development are to

- promote the creation of sustainable human settlements and quality environments;

- contain urban sprawl and promote residential intensification;

- encourage settlement integration and redress the imbalances of the past;

- guide the land-use management system;

- restructure spatially ineffective settlements;

- support the equitable protection of tenure and land-use rights;

- reduce the impact of mining activities on residential environments; and

- promote urban upliftment in certain areas.

The segregated development of the apartheid policy, severe dolomitic conditions and the development of mining villages in close proximity to the respective mining operations largely dictated the urban formation of the region. These elements have created serious fragmentation within urban environments, which, in some cases, will always restrict effective integration.

\section{Funding and human resources}

Lack of funding, human resources and technical expertise is a common difficulty experienced, as mentioned by three of the four participants. The following statements prove this:

"Definitely we don't have enough resources to make ends meet; (ii) I think we try to use our experience to let things happen, and sometimes when I look at things that we have done, I ask myself, how did we manage to do them with such limited staff; (iii) sometimes people misunderstand issues, they see the output that we have had, and then they think if they manage to do $1,2,3$ then they can still manage without no staff, whenever that is not the case, so the thing of staffing needs to be looked at."

The participants agreed that

"services can also be enhanced by training our staff members to provide quality care, efficient care and the Batho Pele principles needs to be looked at." “...support and capacitate our workers because they are still in the old style of just providing services and not necessarily looking for customer care that is needed so much."

Various interventions within the framework of a human resource development plan have been developed. These include an employment equity plan, a skills development plan, career planning and a performance management system.

\section{Research participant 2 emphasized that}

"one must be able to strike a balance of keeping the municipality financially viable while at the same time extend services specially to poor communities where they can not afford to pay for the services."

Funds are needed to give effect to projects that the community is waiting for. If there is a lack of funding, this hampers the visibility of service delivery to the communities.

Over the last few years the capital budget of the District Municipality has declined. Moreover, the new demarcation and the redistribution of duties add to the financial pressure felt by the District Municipality. The district can only survive these pressures by developing sound financial management principles.

There are many challenges to be addressed if the District Municipality is to be a stable and financially sound municipality. These challenges relate to (1) effective collection of levy revenue, (2) collection management, (3) integration of systems, (4) financial viability, (5) sound procurement, and (vi) tendering procedure and process.

The Premier has announced that the Provincial Government through the Municipal Institution Support Centre (MISC) would assist municipalities in this regard. The District Municipality has since put together strategies to ensure that it meets the treasury regulations. The establishment of the budget office will lead to a process of assessing the local municipalities' needs and facilitate the provision of budget and financial control services.

The training and development of staff members are very important because "in leadership, people that are skilled have got expertise, are capable and confident and got vision, so that in return the people that are recruited to the organization have got the necessary skills, necessary expertise, they share in values of the organization, they are willing to go out and do things, and that is the only way you could enhance service delivery".

It was concluded by the research participants that, "for us to be efficient it means doing a number of things. We must have leadership vision because if a person doesn't have vision that person in a leadership position will not be able to inspire and lead the organization, not be able to come up with means, strategies and programs and will not be able to motivate and inspire members of the organization".

\section{Communication}

All the participants mentioned lack of communication as a difficulty that can have an influence on leadership decisionmaking regarding service delivery. Currently there are no formal structures in place to facilitate internal communication. Formal structures such as Section 80 committees serve as a platform for political deliberations - sometimes reluctance of politicians to attend meetings results in decisions not being formalized.

The participants expresses thier concern about communication as follows:

- "I think I speak organizationally there are many obstacles. One of them is communication..."

- "I think communication is very terrible amongst all of us...;

- Communication is very terrible, interaction is very terrible, interface is very bad, sharing of information is very bad, so I think 
that if there was one thing I could rectify, given the opportunity, would be to put in place better communication..."

- "...better communication between ourselves as Strategic Executives to the Municipal Manager and also improve communication between the Municipal Manager and the Executive Mayor as well as with the members of the Mayoral Committee..."

- "...the main obstacle is being uninformed regarding strategic and higher level issues."

Not only have problems been identified, but the research participants also made valuable recommendations on how to optimize service delivery. More specifically, research participant 4 suggested that

"by means of more interaction between top management and personnel, not only through e-mail communication and notification of memoranda, but through effective communication and interaction which will result in officials feeling part and parcel of the organization and the objectives of the organization - remember people will change their behaviour, only if it make a difference for them to do so."

In conclusion: Currently government is clearly seen as an "enabler" of service delivery to its citizens. Municipalities are regarded as vehicles for local economic development, implying that they should create the climate and conditions that are favourable to investment and economic growth. Municipalities should increasingly seek to establish partnerships with other stakeholders in the provision of services through ensuring interaction and communication, and build alliances around local development.

In the South African situation, local economic development is regarded as an important outcome of the integrated development planning process. The municipal planning process should create the platform for putting development issues on the development agenda of a municipality and create opportunities for establishing co-operation and partnerships in support of local development.

\section{DISCUSSION}

The launch of the Local Government White Paper in March 1998 provided a blueprint for final form of local government in South Africa after its progression from apartheid structures, through the democratization of councils, to the creation of developmental local government.

It was clear from the research that within the ambit of developmental local government and the emphasis on visible service delivery, the following aspects need to be addressed:

\section{Highlighting distinctive functions}

The separation of powers between politicians and administrators has been a source of much debate in public policy. According to the District Municipality's Annual Report, there are many models in operation in various governments globally that address the issue in different ways. Some systems enable a greater flow of political input through the top echelons of the administration such as the system in place in the USA where a large part of top management is replaced with each new political administration. Other systems are very clear-cut with regard to the distinction between policy and administration, such as the classic British example where emphasis is placed on the independence of the administration, and its single-minded application of the policy of the day.

The South African model relies heavily on the British model, and the distinction between politicians and administrators is made abundantly clear in legislation starting with the Constitution. What is clear in all international examples of the politics-administration interface is the need to clarify how this relationship will be managed. The District Municipality has come up with the idea of a Roles and Responsibilities handbook to attempt to do this.

The research clearly showed that the key to improving service delivery is the transformation of the institution and re-organization of powers between the District Municipality and the local municipalities. This provides an opportunity for the District Municipalityto deliver quality and equitable services to the communities that it serves through strategic coordination of local municipality programmes. To operationalize these principles and therefore implement the political mandate requires a financially stable municipality and a viable economic environment. The core programme that could deal with these challenges is the Integrated Development Plan.

Section 53 of the Municipal Systems Act (Republic of South Africa, 2000) states that in terms of roles and responsibilities a municipality must, within the legislative framework, define the specific role and area of responsibility of each political structure and political office bearer of the municipality and of the municipal manager.

The respective roles and areas of responsibility of each political structure and political office bearer and of the municipal manager must

- be defined in precise terms by way of separate terms of reference, in writing, for each political structure or political office bearer and the municipal manager; and

- be acknowledged and given effect to in the rules, procedures, instructions, policy statements and other written instruments of the municipality.

Terms of reference may include the delegation of powers and duties to the relevant political structure or political office bearer or municipal manager.

When defining the respective roles and areas of responsibility of each political structure and political office bearer and of the municipal manager, the municipality should determine:

- the relationship between those political structures and political office bearers and the municipal manager, and the manner in which they interact;

- appropriate lines of accountability and reporting for those political structures and political office bearers and the municipal manager;

- mechanisms, processes and procedures for minimizing cross-referrals and overlap of responsibilities between those political structures and political office bearers and the municipal manager;

- mechanisms, processes and procedures for resolving disputes between those political structures and political office bearers and the municipal manager; and

- mechanisms, processes and procedures for interaction between

- those political structures and political office bearers and the municipal manager and other staff members of the municipality; and

- councillors and the municipal manager and other staff members of the municipality.

The assumption was made by research participants that the political head of the council - the executive mayor is responsible for policy matters and outcomes. The head official - the municipal manger is responsible for outputs and implementation and is also the accounting officer. This approach is in line with the approach taken nationally and expressed in the new Public Service Regulations, which rely on a performance driven system based on measurable outputs.

Based on the operating principles of the District Municipality, the following recommendations were made to facilitate co-operation, co-ordination and communication between the political structures, political office bearers and the administration:

- Good working relationships built on mutual trust and with a development-orientated focus; 
- An operational environment shaped by a consultative process and policies;

- A culture of open and mutually respectful communication;

- Honesty, integrity, team work and commitment;

- Adherence to applicable legislation and codes of conduct pertaining to politicians and officials; and

- Commitment to transformation and equity as a yardstick for all organizational processes and delivery.

The way forward is based on the understanding that best practice dictates clear-cut formal systems of interaction and well articulated lines of accountability and reporting mechanisms, with timeous and effective dispute resolution mechanisms. This will improve relationships and minimize tension.

\section{Expediting procedures}

The research has clearly indicated that the only way to expedite producers is to change the administrative mentality of the municipality to that of a developmental mentality. Thus, less of an administrative attitude is needed and more emphasis must be placed on project implementation and delivery of services to the community, especially disadvantaged communities. Here the Batho Pele principles, which emphasize a culture of effective service delivery, could play a major role.

However, this would not be enough to address the problem of tedious procedures. The participants emphasised that it would also be imperative to get a project management and project monitoring unit (PMU) in place. Thus a systems approach based on information technology is needed. The establishment of a PMU to enhance and promote service delivery was an important milestone for the District Municipality.

A PMU is responsible for the administration and financial management of Municipal Infrastructure Grant (MIG) funds, within the municipal and national accounting system for infrastructure projects of the District Municipality and any other municipalities where the PMU has been delegated this authority. The PMU will be responsible for the co-ordination of project based capacity-building and developmental initiatives. The capacity-building components of MIG are only concerned with projects and the arrangements relating to effective municipal infrastructure. It is the responsibility of the PMU to ensure that a municipality has the resources to fulfil the operations and maintenance obligations for all capital projects. The PMU will assist wherever possible with the planning and implementation of operation and maintenance $(\mathrm{O} \& \mathrm{M})$ programmes, directly or indirectly.

It is critical to the success of an $O \& M$ programme that there is appropriate communication and liaison with communities in respect of project planning and implementation. This is needed to ensure buy-in and long-term sustainability of the projects so that the communities can understand the need to pay for services, as well as the development of community-based partnerships for the purposes of $\mathrm{O} \& \mathrm{M}$ programmes.

The following recommendations made by the research participants were seen as an endeavour to fast-track procedures and still be in line with policy stipulations:

- Standards of service need to be defined and the standards must be specific, measurable, achievable, affordable and realistic as well as time bound.

- Powers must be clearly delegated - not only the powers of the District Municipality, but also the responsibilities and functions of political office bearers versus the administration.

\section{Promoting integration and co-ordination}

Municipalities should actively develop ways to co-ordinate resources and investment from the public and private sectors to meet development targets. One of the most important methods for achieving greater co-ordination and integration is integrated development planning. The principles set out in the Development Facilitation Act (Republic of South Africa, 1995) should guide municipalities in building integrated livable settlements.

While strategies for building human settlements may differ between localities, it was clear that the establishment of sustainable and livable settlements depends on the co-ordination of a range of services and regulations, including land-use planning, housing infrastructure, environmental management, transport, health and safety.

\section{Providing funding and human resources}

The effective utilization of funds, resources and expertise is an important success factor for the District Municipality to work towards. Performance budgeting within the Integrated Development Plan (IDP) planning framework is a tool to assist managers in the budgeting process. A budget handbook was developed by the Chief Financial Officer in order for political office bearers and members of the administration to gain an understanding of the following:

- The reasons why we budget;

- Incremental budgeting and its disadvantages

- The change to performance budgeting

- Key performance budgeting concepts

- The micro prioritization process

- The Medium-Term Expenditure Framework

- Activity-based costing

- Zero-based budgeting

- Integration of strategic plans

In analyzing the above, it is evident that developmental local government has four interrelated characteristics: (1) maximizing social development and economic growth; (2) integrating and co-ordinating; (3) democratizing development; and (4) leading and learning.

In the future, developmental local government will therefore have to play a central role in representing our communities, protecting our human rights and meeting our basic needs. It must focus its efforts and resources on improving the quality of life of our communities, especially those members and groups that are most often marginalized or excluded, such as women, disabled people and very poor people.

\section{Improving communication}

One of the outputs arising from the development strategy in the IDP is a communication strategy for the District Municipality and the local authorities. The communication strategy is underpinned by the understanding that integrated regional development is the primary goal of the District Municipality. Integrated regional development should therefore act as catalyst for the communication strategy with the local municipalities that fall within the area of jurisdiction of the District Municipality.

Service delivery is viewed as the mechanism to activate the communication strategy. In other words, communication with the local municipalities is seen as a set of services provided by the District Municipality, the latter facilitating integrated regional development. Services should be understood in terms of the following categories:

- Services provided at the district level, which the local authorities must access;

- Services provided jointly by the district and the local municipalities; and

- Services provided voluntarily at the district level for the benefit of the local municipalities.

The marketing of key services provided by the District Municipality in the interest of integrated regional development should be the focus of the communication strategy. It was 
recommended that the communication strategy should operate on two levels: (1) conventional - using media such as newsletters, interactive web sites, fliers, posters and forums for regular meetings, and (2) strategic - using economies of scale services, legislative innovations, development frameworks and institutional interventions.

The reasoning behind this two-tiered approach to communication is to address different levels of operational capacity at different local municipalities, while maintaining an optimum level of communication, co-operation and integration in planning for the region as a whole. So while some of the local municipalities will require greater assistance from the District Municipality in terms of operational services, others will simply require more and better information.

\section{The development of a model for sustainable service delivery}

According to the Constitution (Republic of South Africa, 1996), a municipality has the right to govern, on its own initiative, the local government affairs of its community, subject to national and provincial legislation. As is clear from this discussion, local government should:

- provide democratic and accountable government for local communities;

- ensure the provision of services to communities in a sustainable manner;

- promote social and economic development;

- promote a safe and healthy environment; and

- encourage the involvement of communities and community organizations in the matters of local government.

More specifically, a municipality has the developmental duty to manage its administration and budgeting and planning processes in such a way that, firstly, the basic needs of the community are prioritized, and, secondly, that the social and economic development of the community is promoted and to participate in national and provincial development programmes is increased.

The vision of the District Municipality is to build a safe and peaceful environment based on sustainable social, economic and physical development, thereby providing a better life for all the people in the area through transparent and accountable governance.

The mission of the institution is to engage in co-operative governance to ensure the development of an environment that enables social, economic and physical development. This will be achieved through the implementation of an integrated development strategy and leveraging of developmental capital and related resources.

The research underlined that in order to reach these goals, municipalities should be able to identify their shortcomings, address the identified problems and consistently monitor their progress. The research clearly showed the need for the development of an integrated model whereby a transformation plan for the municipal area could be developed, implemented and monitored. Such a plan should pertinently address conditions for sustainable service delivery and economic development. More specifically, problems such as those discussed in the above paragraphs should be identified and addressed. To echo the 2008 State of the Nation Address, in order to ensure the speedy, efficient and effective implementation of the necessary policies and programmes we have to substitute business as usual with "business unusual". It is of the utmost importance that municipalities now develop the capacity to transform their resources into strategies (Mbeki, 2008).

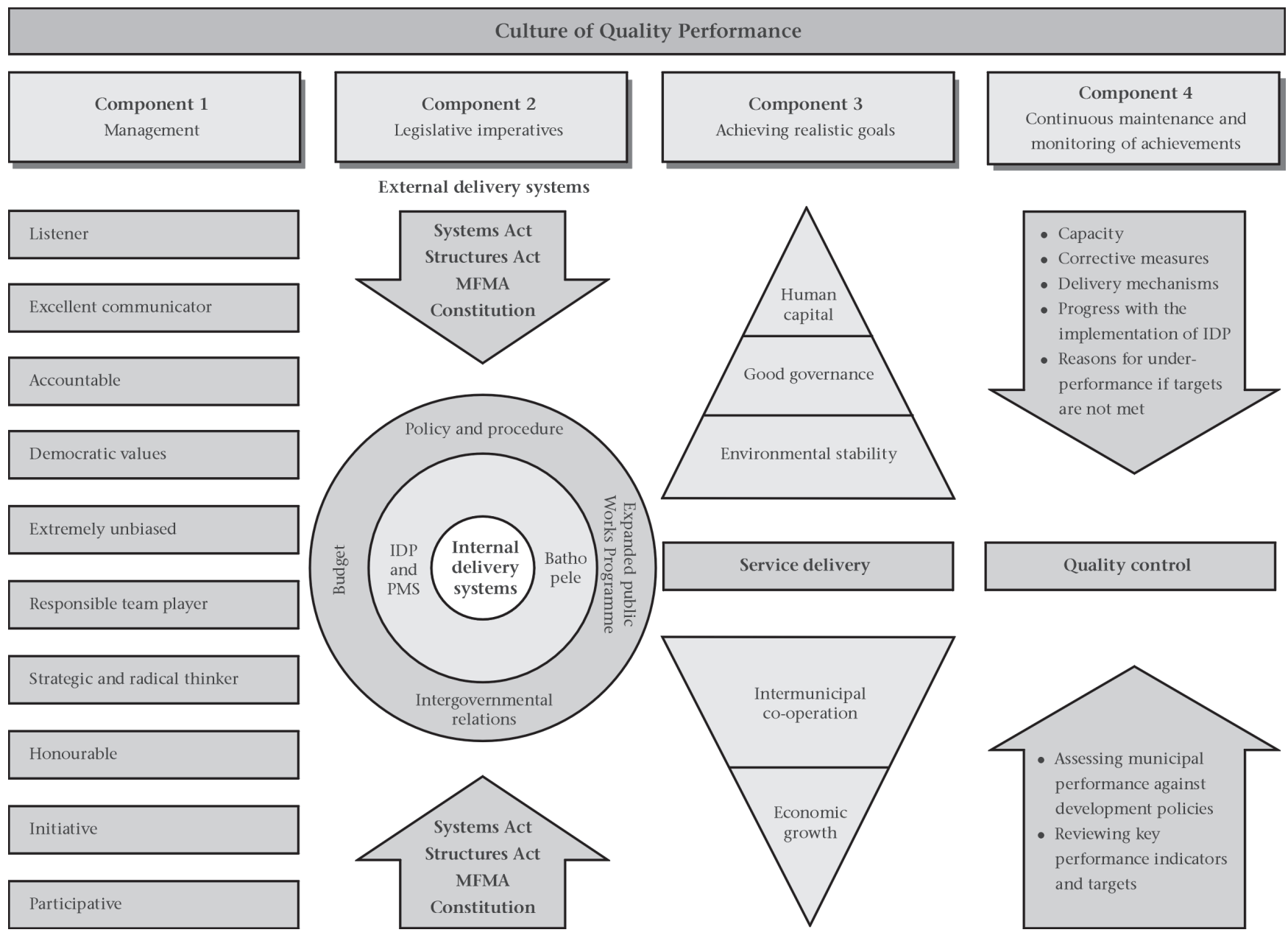

Figure 1: Retro Advanced Leadership Model 
The outcome of this research was the development of a model, the Retro Advanced Leadership Model, which is aimed at helping municipalities to meet their goals. These goals include the following: good governance, developing human resources, environmental stability, intermunicipal co-operation, economic development, public participation and programme management.

The Retro Advanced Leadership Model (see Figure 1) presents the key components for enhancing service delivery in local government identified in the study, namely (1) management of leadership performance; (2) legislative imperatives; (3) achieving realistic goals; and (4) continuous maintenance and monitoring of achievements has been identified.

This model has been derived from the participants' viewpoints and experiences of service delivery in local government and how it could be enhanced. The model is a modest theoretical contribution in that it places the focus on the following aspects of service delivery:

- The creation or strengthening of a culture of performance excellence amongst employees;

- Leadership qualities that lead to service delivery excellence;

- The contribution of internal systems (policy, procedures, budget, integrated development planning and the performance management system) to intergovernmental relations and infrastructure development;

- Legislation that stipulates local government's responsibility and accountability in terms of service delivery;

- The importance of human capital, good governance, environmental stability and economic growth for achieving realistic service delivery goals; and

- The need for continuous monitoring to maintain and enhance the quality of service delivery.

The a model should thus enable the District Municipality to

- address management and leadership performance;

- adhere to and incorporate national and provincial legislation and utilize and meet all legislative requirements that drive external and internal delivery systems;

- set clear, realistic goals to meet the service needs of the people;

- link, integrate and co-ordinate all programmes and take into account proposals for the development of the municipality;

- align the resources and capacity of the municipality with the implementation of the Integrated Development Plan;

- form the policy framework and general basis on which annual budgets must be based;

- make provision for continuous monitoring of achievements;

- comply with national and provincial development plans and planning requirements;

- establish a performance management system that would set appropriate key performance indicators and measurable performance targets with regard to each of the development priorities and objectives;

- evaluate progress against the key performance indicators;

- review its performance and take steps to improve performance with regard to those development priorities and objectives that were not met;

- establish a process of regular reporting to

- the Council, other political structures and political office bearers

- staff of the municipality; and

- the public and appropriate organs of state.

- monitor the management of the District Municipality's administration in accordance with the directions of the Council.

It was clear from the research that performance on a local government level depends to a large extent on the quality of leadership provided by the executive and senior management.

\section{Noticeable limitations of the research}

The purpose of the research was to add value to the current vision of the District Municipality, not only to achieve the good governance objectives mentioned in the Constitution, but also to provide affordable services to its communities.

The model that was developed is to a large extent governed by the viewpoints and inputs of the participants. therefore it does not imply that the model could be implemented as a general tool to enhance service delivery in all local government. It could however be customized to address the needs of other local government institutions, provided that their specific culture, political viewpoint and service delivery objectives form the core elements for adaptation.

\section{Suggestions for further research}

The suggestions below are set out in line with component 3 of the Retro Advanced Leadership Model, namely "Achievement of realistic goals".

Faster economic growth: In prioritizing the enhancement of service delivery, macro economic plans to address poverty and unemployment in the district do not attract sufficient attention. These macro economic plans, their potential and their application are to be investigated.

Environmental stability: Multisectoral partnerships based on the Spatial Development Framework could ensure better integration and co-ordination of sector initiatives to create sustainable communities. Such partnerships should be investigated.

Human capital: The development of a healthy, skilled and productive workforce should be investigated to ensure that the basic needs of the communities are met.

Good governance: Stakeholder participation in the Integrated Development Plan should be extended beyond its compilation to include its implementation and monitoring. The role of councillors in this regard should therefore be investigated.

Intermunicipal co-operation: The alignment between the priorities and activities of the local municipalities and the District Municipality and the impact of this alignment on visible service delivery should be examined.

\section{REFERENCES}

Athens, L.A. (1984) Scientific criteria for evaluating qualitative studies. In: N.K. Denzin (Ed.), Studies in Symbolic Interaction. Greenwich: JAI Press.

Batho Pele principles (http://www.dpsa.gov.za/batho-pele/index. asp).

Becker, H.S. (1970) Practitioners of vice and crime. In: R.W Habenstein (Ed.), Pathways to data: Field methods for studying ongoing organisations. Chicago: Aldine Publications.

Bogdan, R. \& Taylor, S.J. (1975) Introduction to qualitative research methods: A phenomenological approach to the social sciences. Chicago: University of Chicago.

Bogdan, R.C. \& Biklen S.K. (1998) Qualitative Research for Education. An Introduction to Theory and Methods. United States of America: Allyn \& Bacon.

Burden, F.J. (2005) The Development of an Organisational Redesign Model: A South African Case Study. (Unpublished dissertation.) Johannesburg: University of Johannesburg.

Claassen, G. (2004) Male menopause and decision-making: A qualitative study. (Unpublished dissertation.) Johannesburg: Rand Afrikaans University.

Cohen, M.Z. (2002) Introduction to qualitative research. In: G. LoBiondo-Wood \& J. Haber (Eds), Nursing Research. Methods, Critical Appraisal and Utilisation. 4th ed. St Lois: Mosby.

Creswell, J.W. (1998) Qualitative inquiry and research design. Choosing among five traditions. London: Sage Publications.

Day, D.V., Zaccaro, S.J. \& Halpin, S.M. (2004) Leader development for transforming organizations. Growing leaders for tomorrow. London: Lawrence Erlbaum Associates Publishers. 
Denscombe, M. (1998) The good research guide for small-scale social research projects. Buckingham: Open University.

Department of Public Service and Administration (2004) Batho Pele Handbook. A service delivery improvement guide. Pretoria: Resolve Training Works.

Dey, I. (1999) Grounding Grounded Theory - Guidelines for Qualitative Inquiry. San Diego: Academic Press.

District Municipality (2004) Draft copy of the Integrated Development Plan (IDP). South Africa: District Municipality.

Glaser, B.G. (1978) Theoretical Sensitivity. Mill Valley, CA: Sociology Press.

Glaser, B. \& Strauss, A. (1967) The discovery of grounded theory strategies for qualitative research. Chicago: Aldine.

Goulding, C. (2002) Grounded Theory - A Practical Guide for Management, Business and Market Researchers. London: Sage Publications Ltd.

Guba, E. \& Lincoln, Y. (1994) Competing paradigms in qualitative research. In: N.K. Denzin \& T.S. Lincoln (Eds), Handbook of qualitative research. Thousand Oaks, CA: Sage Publications.

Holloway, I. \& Wheeler, S. (2002) Qualitative research in nursing. 2nd ed. Oxford: Blackwell Science Ltd.

Lincoln, Y.S. \& Guba, E.G. (1985) Naturalistic enquiry. Beverly Hills, CA: Sage Publications.

Locke, K. (2001) Grounded theory in management research. Thousand Oaks: Sage Publications.

Lofland, J. (1971) Analyzing social settings. Belmont, CA: Wadsworth Publishing Co.

Lofland, J. \& Lofland, L. (1995) Analyzing social settings: A guide to qualitative observations and analysis. 3rd ed. Belmont, CA: Wadsworth Publishing Co.

Mbeki, T. (2008) State of the Nation (SON) Address. Retrieved 10 March 2008 from http://www.info.gov.za/speeches/son/ index.html.

Mouton, J. \& Marais, H.C. (1989) Metodologie van die geesteswetenskappe: Basiese begrippe. [Methodology of the human sciences: Basic concepts.] Pretoria, Raad vir Geesteswetenskaplike Navorsing.

Mouton, J. \& Marais, H.C. (1990) Basic concepts in the methodology of the social sciences. Pretoria: HSRC Publishers.

Mufamadi, F.S. (2005) Speech delivered by Minister FS Mufamadi on the debate of the State of the Nation Address. Retrieved on 10 March 2008 fromhttp://www.info.gov.za/ speeches/2005/05021608151001.htm.

Nell, T.L. (2005) A case study on the development of an organisational development model for a South African financial institution. (Unpublished dissertation.) Johannesburg: University of Johannesburg.

Neuman, W.L. (2003) Social Research Methods: Qualitative and Quantitative Approaches. 5th ed. Boston: Allyn \& Bacon.
Polit, D.F., Beck, C.T. \& Hungles, B.P. (2001) Essentials of nursing research: Methods, Appraisal and Utilization. 5th ed. Philadelphia: Harper Collins Publisher.

Pretorius, E.M. (2006) The role of leadership in enhancing service delivery in local government. (Unpublished dissertation.) Johannesburg: University of Johannesburg.

Republic of South Africa (1995) Development Facilitation Act, Act 67 of 1995. Retrieved on 10 March, 2008 from http:// www.kzntransport.gov.za/reading_room/acts/national/ DevelopmentFacilitiationActRegulations.pdf.

Republic of South Africa (1996) Constitution of the Republic of South Africa, Act 108 of 1996. Retrieved on 10 March, 2008 from http://www.info.gov.za/documents/constitution/ index.htm.

Republic of South Africa (1998) Local Government: Municipal Structures Act, Act 117 of 1998, Government Gazette No 19614 , 18 December 1998.

Republic of South Africa (2000) Local Government: Municipal Systems Act, Act 32 of 2000, Government Gazette No 21776, 30 November 2000.

Republic of South Africa (2004) Intergovernmental Relations Framework Bill (B3B - 2005), Government Gazette No 27031, of 26 November 2004.

Schurink, W.J. (1989) Die realiteit van homoseksualisme: 'n Sosiologieskwalitatiewe ontleding. [The reality of homosexualism: A sociological-qualitative analysis.] (Unpublished dissertation). Potchefstroom University for Christian Higher Education.

Schurink, W.J. (2005) Experiencing qualitative research. Winter Methodology School. Notes to D and M students, University of Johannesburg.

Schwandt, T.A. (2007) The Sage dictionary of qualitative inquiry. London: Sage Publications.

Seale, C. (1999) The quality of qualitative research. London: Sage Publications.

Silverman, D. (2000) Doing Qualitative Research: A practical handbook. London: Sage Publications.

Strauss, A. (1987). Qualitative research for social scientists. Cambridge, UK: Cambridge.

Strauss, A. \& Corbin J. (1990) Basics of Qualitative Research. Grounded Theory Procedures and Techniques. London: Sage Publications.

Taylor, S.J. \& Bogdan, R. (1995) The variety of community experience. Qualitative studies of family and community life. Baltimore: Paul H. Brookes Publishing Co.

Vil-Nkomo, S. (1997) Meeting the challenges of the new millennium in governance and public sector development. Pretoria: University of Pretoria.

Yin, R.K. (1994) Case Study Research - Design and Methods. Thousand Oaks: Sage Publications.

Zimmerman, D.H. \& Wieder, D.L. (1977) The Diary. Urban Life, 5(4), pp. 479-497. 